\title{
Unexpected Diagnosis of Pulmonary Tuberculosis During Bronchoscopy Using Radial Probe Endobronchial Ultrasound
}

Hyun Sung Chung

Pusan National University School of Medicine

\section{Soohyun Bae}

Ulsan University Hospital

Insu Kim

Dong-A University Medical Center

Hyo Yeong Ahn

Pusan National University School of Medicine

Jung Seop Eom ( $\nabla$ ejspulm@gmail.com )

Pusan National University School of Medicine https://orcid.org/0000-0002-0832-1314

\section{Research}

Keywords: Bronchoscopy, Diagnosis, Lung neoplasm, Tuberculosis, Ultrasonography

Posted Date: September 17th, 2020

DOl: https://doi.org/10.21203/rs.3.rs-76693/v1

License: (a) (i) This work is licensed under a Creative Commons Attribution 4.0 International License. Read Full License 


\section{Abstract}

Background: Bronchoscopy using radial probe endobronchial ultrasound (EBUS) is performed when a peripheral lung lesion (PLL) is suspected to be malignant. However, pulmonary tuberculosis is unexpectedly diagnosed in some patients, and healthcare workers could therefore be exposed to tuberculosis if sufficient precautions are not taken. In this study, we examined the incidence of and factors associated with unexpected diagnosis of pulmonary tuberculosis during bronchoscopy using radial probe EBUS.

Methods: This retrospective study included 970 patients who received bronchoscopy using radial probe EBUS between December 2015 and November 2018. Clinical, histological, radiological, and microbiological data were reviewed.

Results: Pulmonary tuberculosis was unexpectedly diagnosed in 31 patients (3.2\%) during bronchoscopy using radial probe EBUS. Patients with a lower age were significantly more likely to be diagnosed with tuberculosis than elderly patients (odds ratio [OR], 0.951; 95\% confidence interval [Cl], 0.924-0.978; $P=$ $0.001)$. Among the various $C T$ findings, a low HUs difference between pre- and post-enhanced CT (OR, $0.976 ; 95 \% \mathrm{Cl}, 0.955-0.996 ; P=0.022)$, the presence of concentric cavitation (OR, $5.211 ; 95 \% \mathrm{Cl}, 1.447-$ $18.759 ; P=0.012)$, and the presence of satellite centrilobular nodules $(\mathrm{OR}, 22.925 ; 95 \% \mathrm{Cl}, 10.556-$ 49.785; $P<0.001$ ) were independently associated with unexpected diagnosis of tuberculosis.

Conclusions: The risk of healthcare workers being exposed to Mycobacterium tuberculosis during bronchoscopy using radial probe EBUS has been underestimated. Our results suggest that healthcare workers in the bronchoscopy suite should consider high-grade respiratory protection when examining patients with risk factors for an unexpected diagnosis of pulmonary tuberculosis.

\section{Background}

The American College of Chest Physicians and American Association for Bronchology Consensus Statement recommends that healthcare workers should wear an N95 particulate respirator or highergrade respiratory protection to prevent bronchoscopy-associated Mycobacterium tuberculosis infection during bronchoscopy of patients with suspected pulmonary tuberculosis [1]. However, in some patients, pulmonary tuberculosis is unexpectedly diagnosed from bronchoscopy samples when the patient was not initially thought to be suffering from tuberculosis. ${ }^{2}$ Previous studies reported that healthcare workers in the Republic of Korea, which is an intermediate tuberculosis prevalence region (59/100 000 persons per year, 2019), have at least a 4-6\% chance of inadvertent exposure to Mycobacterium tuberculosis during conventional bronchoscopy [2-4].

Novel bronchoscopy modalities for the diagnosis of peripheral lung lesions (PLLs) have been developed over the past 20 years, and include electromagnetic navigational bronchoscopy and virtual bronchoscopy navigation [5]. In particular, bronchoscopy using radial probe endobronchial ultrasound (EBUS) is considered to be a reasonable diagnostic approach with an acceptable diagnostic yield and low 
complication rate [6-8]. Although bronchoscopy using radial probe EBUS is generally performed when lung cancer is suspected, previous studies reported that bronchoscopy samples obtained using radial probe EBUS resulted in a final diagnosis of pulmonary tuberculosis in $3.9-11.0 \%$ of patients [9-15].

Because of the widespread use of low-dose computed tomography (CT) for lung cancer screening in high risk patients, the use of radial probe EBUS bronchoscopy for the diagnosis of PLLs has also increased $[16,17]$. However, there is little known about the unexpected diagnosis rates of pulmonary tuberculosis during bronchoscopy using radial probe EBUS for PLLs. Therefore, we performed a multicenter retrospective study to identify the incidence of unexpected diagnoses of pulmonary tuberculosis and the factors associated with an increased probability of it during bronchoscopy using radial probe EBUS.

\section{Methods}

\section{Study population}

This retrospective study was conducted using the bronchoscopy databases of Pusan National University Hospital (a university-affiliated tertiary referral hospital in Busan, Republic of Korea) and Ulsan University Hospital (a university-affiliated secondary referral hospital in Ulsan, Republic of Korea) for the period December 2015 to November 2018. During the study period, 993 patients with PLL (797 and 196 patients at Pusan National University and Ulsan University Hospitals, respectively) received bronchoscopy using radial probe EBUS. Among them, 23 patients were excluded because lung cancer was previously confirmed and the radial probe EBUS bronchoscopy was performed as a re-biopsy for the identification of T790M mutation of epidermal growth factor receptor [18]. This left 970 patients for selection for the study. Some of the clinical data on the patients enrolled between 2015 and 2018 was included in two articles published in 2018 and 2019 [8,19]. This study was approved by the institutional review boards of Pusan National University Hospital (IRB no. 1906-033-080) and Ulsan University Hospital (IRB no. 202007-011). As this study was performed retrospectively, the requirement for informed patient consent was waived.

\section{Analysis of the CT scans}

PLL was defined as an intrapulmonary lesion existing beyond the segmental bronchus that is generally invisible on conventional bronchoscopy [20]. The mean diameter of a PLL was defined as the average of its maximum and vertical diameter. A positive bronchus sign was defined as the presence of a bronchus leading directly to the PLL [21]. The margin of the PLL was classified as follows [22,23]: 1) smooth when the margin was well-demarcated with round or oval-shape curves; 2 ) lobulated when the margin was distinguished by some smooth and relatively large convexities; 3 ) spiculated when the margin was irregular and had multiple radiating strands; and 4) pneumonic consolidation when the margin could not be distinguished because of surrounding consolidation. PLLs were classified as solid, part-solid, or ground-glass opacity according to a visual assessment method based on CT attenuation [24]. The distance from the pleura was measured as the closest distance between the PLL and the visceral pleura. 
The Hounsfield units (HU) of the PPL on pre- and post-enhancement CT phases were measured using mediastinal window images to minimize volume averaging [25].

If the lesion showed cavitation, the maximal thickness of the cavity wall was measured, and it was classified as concentric cavitation if the wall thickness was uniform, or eccentric cavitation otherwise [26]. The following accompanying CT findings were also analyzed: 1) presence of a satellite centrilobular nodule; 2) bronchiectasis; 3 ) anthracofibrosis of the airway; 4) pulmonary emphysema; 5) fibrocalcific tuberculosis; 6) interstitial lung diseases; 7) atelectasis; and 8) pleural effusion (Additional file 1).

\section{Bronchoscopic procedure and specimens}

All patients underwent bronchoscopy with a 4.0-mm-sized flexible bronchoscope (BF-P260F; Olympus, Tokyo, Japan) after conscious sedation with midazolam and fentanyl. For local anesthesia, $2 \%$ lidocaine was injected into the tracheobronchial tree via the working channel of the bronchoscope. After airway inspection, the bronchoscope was advanced as far as possible into the bronchus of the target lesion under CT image guidance. Thereafter, a 20-MHz radial probe EBUS (UM-S20-17S; Olympus, Tokyo, Japan) covered by a guide sheath (K-201; Olympus, Tokyo, Japan) was advanced through the working channel until resistance was met. Then, under $\mathrm{X}$-ray fluoroscopic guidance, the radial probe EBUS was pulled back slightly to acquire the ultrasound images [10]. Radial probe EBUS images were classified as: 1) within; 2) adjacent; or 3) invisible, as described previously [14]. When the location of the target lesion was identified, the radial probe was retrieved with the guide sheath being kept in place. Brushing cytology and a forceps biopsy were then performed through the guide sheath under fluoroscopic guidance. After obtaining the cytology and biopsy samples, the guide sheath was removed and bronchial washing of the target lesion was performed through the working channel with $5 \mathrm{ml}$ of sterile saline.

The bronchial washing fluids were used to perform an acid-fast bacillus smear with culture and a realtime polymerase chain reaction (PCR) for mycobacterium. Fluorescence microscopy with auraminerhodamine staining was used for the acid-fast bacillus smear. Both solid (3\% Ogawa medium) and liquid medium (BACTEC MGIT 960 system; Becton Dickinson Microbiology Systems, Sparks, MD) were used for the mycobacterium culture. A real-time PCR for mycobacterium (AdvanSure TB/NTM real-time PCR kit; LG Life Science, Seoul, Republic of Korea) was also performed on the bronchial washing fluid.

If a final diagnosis could not be determined from the bronchoscopic samples, an additional percutaneous needle biopsy or surgical biopsy was performed. When the pathological findings of the percutaneous needle biopsy or surgical biopsy specimens were suspicious for tuberculosis, such as the presence of chronic granulomatous inflammation, PCR (MTB-PCR kit; Biosewoom, Seoul, Republic of Korea) was additionally performed on the tissue specimen, at the discretion of the pathologist.

\section{Diagnosis of pulmonary tuberculosis}

Tuberculosis was diagnosed as follows: 1) Mycobacterium tuberculosis was cultured from the bronchial washing fluid; and 2) PCRs for Mycobacterium tuberculosis using either the bronchial washing fluid or 
tissue specimen were positive and clinicoradiological improvements were achieved after standard antituberculosis treatment [27].

\section{Statistical analysis}

Statistical analyses were performed using R version 3.6.6 (R-Project, GNU GPL). All results are presented as number and percentage for categorical variables and median with interquartile range [IQR] for continuous variables. Data comparisons were made using $\chi 2$ or Fisher's exact tests for categorical variables, and independent $t$-tests or Wilcoxon rank-sum tests for continuous variables. Multivariate logistic regression analysis was performed using factors with a $P$-value $<0.1$ in the univariate analysis, to identify independent factors related to unexpected diagnosis of pulmonary tuberculosis. $P$-values $<0.05$ were considered statistically significant. Receiver operating characteristics curves were plotted to calculate the area under the curve, Youden index, sensitivity, and specificity.

\section{Results}

\section{Baseline characteristics}

The baseline characteristics of the 970 patients are shown in Table 1. The median age was 69 years (IQR, 61-76) and $62.4 \%$ of patients were of male gender. The most frequent PLL margin type on CT was a lobulated type, which was shown in 450 patients (46.4\%). Solid lesions were the most common opacity, being found in 812 patients (83.7\%). The median mean diameter of the PLLs was $27.1 \mathrm{~mm}$ (IQR, 19.4$37.8 \mathrm{~mm}$ ), and the median distance from the pleura was $8.0 \mathrm{~mm}$ (IQR, 0.0-20.1 mm). One hundred and twenty patients $(12.4 \%)$ had cavity formation, and $22(18.3 \%)$ of these had concentric cavitation. A positive bronchus sign on CT was found in 898 patients (92.5\%). The most frequent accompanying CT finding was pulmonary emphysema, which occurred in 266 patients (27.4\%), followed by anthracofibrosis in 154 patients $(15.8 \%)$, atelectasis in 103 patients (10.6\%), and fibrocalcific tuberculosis in 99 patients (10.2\%; Additional file 2). 
Table 1

Baseline characteristic of the 970 study patients

\section{Variables}

Age, years

Male gender

Location

Right upper lobe

Right middle lobe

Right lower lobe

Left upper lobe

Left lower lobe

Margin of peripheral lung lesion

Smooth

Lobulated

Spiculated

Pneumonic consolidation

CT Opacity

Solid

Mixed

Ground-glass opacity

Mean diameter, $\mathrm{mm}$

Distance from pleura, $\mathrm{mm}$

Difference in Hounsfield unit*

Cavity formation

Cavity wall thickness, $\mathrm{mm}$

Concentric cavitation $^{\dagger}$

Positive bronchus sign on CT
No. (\%), or median (interquartile range)

$69(61-76)$

$605(62.4)$

$271(27.9)$

$73(7.5)$

$231(23.8)$

$248(25.2)$

$147(15.2)$

$161(16.6)$

$450(46.4)$

$266(27.4)$

$93(9.6)$

$812(83.7)$

$140(14.4)$

$18(1.9)$

$27.1(19.4-37.8)$

$8.0(0.0-20.1)$

$28.7(12.7-46.3)$

$120(12.4)$

$14.8(8.0-19.1)$

$22 / 120(18.3)$

$898(92.5)$

*Differences in Hounsfield units between pre- and post-enhancement images were measured in 817 patients $(84.2 \%)$.

tData are presented as No./total (\%). 


\section{Variables}

Endobronchial ultrasound images

Within lesion

Adjacent to lesion

Invisible lesion

*Differences in Hounsfield units between pre- and post-enhancement images were measured in 817 patients $(84.2 \%)$.

tData are presented as No./total (\%).
No. (\%), or median (interquartile range)

$807(83.0)$

$137(14.1)$

$26(2.7)$

\section{Overall diagnosis}

Pulmonary tuberculosis was unexpectedly diagnosed in 31 patients (3.2\%) who received bronchoscopy using radial probe EBUS (Table 2). Mycobacterium tuberculosis was cultured from the bronchial washing specimens of 28 patients ( $90.3 \%$ ), and the PCR for mycobacterium was positive in 25 patients $(80.6 \%)$. Culture and PCR for mycobacterium using the bronchial washing fluid were both positive in 19 patients (61.3\%). Using the surgical specimen, PCR for Mycobacterium tuberculosis was positive in four patients (12.9\%), and all were diagnosed with pulmonary tuberculosis with compatible histological findings. Two patients had both lung cancer and pulmonary tuberculosis. Otherwise, lung cancer was diagnosed in 691 patients $(71.2 \%)$, followed by benign disease such as organizing pneumonia and nontuberculous mycobacterium lung disease in 35 patients (3.6\%), and metastatic cancer from an extrathoracic malignancy such as colon cancer, breast cancer, or lymphoma in 24 patients $(2.5 \%$; Table 3$)$.

Table 2

Diagnostic methods in the 31 patients with pulmonary tuberculosis

\begin{tabular}{|ll|}
\hline Diagnostic method & No. (\%) \\
\hline Bronchial washing specimen & \\
\hline Mycobacterium tuberculosis-positive culture & $28(90.3)$ \\
\hline PCR positive for mycobacterium & $25(80.6)$ \\
\hline Tissue specimen & \\
\hline PCR positive for mycobacterium & $4(12.9)$ \\
\hline PCR = polymerase chain reaction. \\
\hline
\end{tabular}


Table 3

Overall diagnoses of the 970 study patients

\begin{tabular}{|l|l|}
\hline Diagnosis & No. (\%) \\
\hline Malignant disease & \\
\hline Lung cancer* & $693(71.4)$ \\
\hline Colon cancer & $5(0.5)$ \\
\hline Breast cancer & $4(0.4)$ \\
\hline Sarcoma & $3(0.3)$ \\
\hline Lymphoma & $3(0.3)$ \\
\hline Thyroid cancer & $2(0.2)$ \\
\hline Malignant melanoma & $1(0.1)$ \\
\hline Renal cell carcinoma & $1(0.1)$ \\
\hline Mesothelioma & $1(0.1)$ \\
\hline PEComatous tumor & $1(0.1)$ \\
\hline Cervical cancer & $1(0.1)$ \\
\hline Bladder cancer & $1(0.1)$ \\
\hline Endometrial cancer & $1(0.1)$ \\
\hline Benign disease & $1(0.4)$ \\
\hline Pulmonary tuberculosis* & $1(0.1)$ \\
\hline Nontuberculous mycobacteria & $31(3.2)$ \\
\hline Organizing pneumonia & $10(1.0)$ \\
\hline Necrotizing pneumonia & $10(1.0)$ \\
\hline Aspergilloma & $4(0.4)$ \\
\hline Bronchiolitis obliterans organizing pneumonia & $4(0.4)$ \\
\hline Sarcoidosis & $2(0.2)$ \\
\hline Cryptococcus & $1(0.1)$ \\
\hline Fungal infection & $1(0.1)$ \\
\hline Earasite infection & 1 simultaneously. \\
\hline
\end{tabular}




\begin{tabular}{|lc|}
\hline Diagnosis & No. (\%) \\
\hline Unknown & $189(19.5)$ \\
\hline *Two patients had both lung cancer and pulmonary tuberculosis simultaneously. \\
\hline
\end{tabular}

\section{Factors associated with pulmonary tuberculosis}

Univariate analysis showed that the patients with pulmonary tuberculosis were significantly younger than those without pulmonary tuberculosis (61 yrs vs. $68 \mathrm{yrs}, P=0.004$; Table 4). There was a significant difference in the PPL margin between patients with and without tuberculosis $(P=0.007)$. The difference in HUs between pre- and post-enhancement images was significantly lower in patients with pulmonary tuberculosis than in those without tuberculosis $(15.0$ vs. 29.0, $P=0.026)$. In patients with a cavitary lesion, the proportion of lesions showing concentricity was significantly higher in those patients with tuberculosis than in those without tuberculosis $(50.0 \% v s .16 .7 \%, P=0.040)$. Patients with pulmonary tuberculosis had a higher probability of having a satellite centrilobular nodule on CT than those without pulmonary tuberculosis $(67.7 \%$ vs. $7.2 \%, P<0.001)$. 
Table 4

Data of the patients with and without pulmonary tuberculosis

\begin{tabular}{|c|c|c|c|}
\hline Variables & $\begin{array}{l}\text { With pulmonary tuberculosis } \\
(n=31)\end{array}$ & $\begin{array}{l}\text { Without pulmonary tuberculosis } \\
(n=939)\end{array}$ & $P$-value \\
\hline Age, years & $61(49-72)$ & $68(61-76)$ & 0.004 \\
\hline Male gender & $22(70.9)$ & $583(62.1)$ & 0.737 \\
\hline Location & & & 0.635 \\
\hline Right upper lobe & $8(25.8)$ & $263(28.0)$ & \\
\hline Right middle lobe & $2(6.5)$ & $71(7.6)$ & \\
\hline Right lower lobe & $5(16.1)$ & $226(24.1)$ & \\
\hline Left upper lobe & $9(29.0)$ & $239(25.5)$ & \\
\hline Left lower lobe & $7(22.5)$ & $140(14.9)$ & \\
\hline Margin & & & 0.007 \\
\hline Smooth & $6(19.3)$ & $155(16.5)$ & \\
\hline Lobulated & $7(22.5)$ & $443(47.2)$ & \\
\hline Spiculated & $11(35.4)$ & $255(27.2)$ & \\
\hline Pneumonic consolidation & $7(22.6)$ & $86(9.2)$ & \\
\hline CT opacities & & & 0.307 \\
\hline Solid & $29(93.5)$ & $783(83.3)$ & \\
\hline Mixed & $1(3.2)$ & $139(14.8)$ & \\
\hline Ground-glass opacity & $1(3.2)$ & $17(1.8)$ & \\
\hline Mean diameter, $\mathrm{mm}$ & $26.5(17.3-45.9)$ & $27.2(19.7-37.7)$ & 0.799 \\
\hline Distance from pleura, $\mathrm{mm}$ & $5.4(0.0-18.3)$ & $8.0(0.0-20.1)$ & 0.409 \\
\hline Difference in Hounsfield units* & $15.0(3.3-44.4)$ & $29.0(13.0-46.4)$ & 0.026 \\
\hline Cavity formation & $6(19.4)$ & $114(12.1)$ & 0.446 \\
\hline Concentric cavitation $^{\dagger}$ & $3 / 6(50.0)$ & 19/114 (16.7) & 0.040 \\
\hline Positive bronchus sign on CT & $31(100.0)$ & $867(92.2)$ & 0.521 \\
\hline Endobronchial ultrasound images & & & 0.488 \\
\hline Within lesion & $25(80.6)$ & $782(83.2)$ & \\
\hline Adjacent to lesion & $4(12.9)$ & $133(14.2)$ & \\
\hline Invisible lesion & $2(6.5)$ & $24(2.6)$ & \\
\hline \multicolumn{4}{|l|}{ Companion CT findings } \\
\hline Satellite centrilobular nodule & $21(67.7)$ & $68(7.2)$ & $<0.001$ \\
\hline Bronchiectasis & $2(6.5)$ & $35(3.7)$ & 0.823 \\
\hline Anthracofibrosis & $1(3.2)$ & $153(16.3)$ & 0.070 \\
\hline Pulmonary emphysema & $7(22.5)$ & $259(27.5)$ & 0.538 \\
\hline Fibrocalcific tuberculosis & $6(19.3)$ & $93(9.9)$ & 0.212 \\
\hline Interstitial lung disease & $0(0.0)$ & $35(3.7)$ & 0.512 \\
\hline Atelectasis & $2(6.5)$ & $101(10.7)$ & 0.564 \\
\hline Pleural effusion & $4(12.9)$ & $79(8.4)$ & 0.668 \\
\hline $\begin{array}{l}{ }^{*} \text { Differences in Hounsfield units be } \\
\text { patients }(84.2 \%) \text {. }\end{array}$ & etween pr & & \\
\hline
\end{tabular}

Multivariate logistic regression analysis was conducted to identify independent factors associated with unexpected diagnosis of pulmonary tuberculosis (Table 5). The results revealed that a younger age was significantly associated with a higher chance of tuberculosis diagnosis (odds ratio [OR], $0.951 ; 95 \%$ confidence interval [Cl], 0.924-0.978; $P=0.001)$. Among the various CT findings, a lower difference in HUs between pre- and post- enhancement images (OR, 0.976; 95\% $\mathrm{Cl}, 0.955-0.996 ; P=0.022)$, the presence of concentric cavitation (OR, 5.211;95\% Cl, 1.447-18.759; $P=0.012)$, and the presence of satellite centrilobular nodules $(\mathrm{OR}, 22.925 ; 95 \% \mathrm{Cl}, 10.556-49.785 ; P<0.001)$ were independently associated with an unexpected diagnosis of pulmonary tuberculosis during bronchoscopy using radial probe EBUS. 
Table 5

Logistic regression analysis to identify factors associated with pulmonary tuberculosis

\begin{tabular}{|c|c|c|}
\hline Variables & Odds ratio ( $95 \%$ confidence interval) & $P$-value \\
\hline Age (per year) & $0.951(0.924-0.978)$ & 0.001 \\
\hline Margin & & \\
\hline Smooth vs. Lobulated & $0.412(0.136-1.244)$ & 0.116 \\
\hline Smooth vs. Spiculated & $1.122(0.407-3.093)$ & 0.825 \\
\hline Smooth vs. Pneumonic consolidation & $2.116(0.689-6.479)$ & 0.190 \\
\hline Difference in Hounsfield units* (per digit) & $0.976(0.955-0.996)$ & 0.022 \\
\hline Concentric cavitation $^{\dagger}$ & $5.211(1.447-18.759)$ & 0.012 \\
\hline Satellite centrilobular nodule & $22.925(10.556-49.785)$ & $<0.001$ \\
\hline Bronchiectasis & $0.836(0.111-6.303)$ & 0.862 \\
\hline Anthracofibrosis & $0.171(0.023-1.265)$ & 0.084 \\
\hline Fibrocalcific tuberculosis & $2.183(0.873-5.459)$ & 0.095 \\
\hline $\begin{array}{l}\text { Differences in Hounsfield units between } \\
\text { patients }(84.2 \%) \text {. }\end{array}$ & post-enhancement im & \\
\hline $\begin{array}{l}\text { atients with and without tuber } \\
\text { ectively. }\end{array}$ & & \\
\hline
\end{tabular}

Receiver operating characteristics curves based on age and the difference in HUs between pre- and postenhancement images are shown in Fig. 1. For age and the difference in HUs, the areas under the curve were 64.6 (sensitivity $48.4 \%$; specificity $80.5 \%$ ) and 64.9 (sensitivity $44.0 \%$; specificity $89.8 \%$ ), respectively. Analysis of the Youden's index indicated that the optimal cut-off values for age and the difference in HUs for predicting unexpected diagnosis of pulmonary tuberculosis were 58.5 and 4.8, respectively.

\section{Discussion}

In this study, the incidence of unexpected diagnosis of pulmonary tuberculosis during radial probe EBUS bronchoscopy for PLL was 3.2\%. Our results indicate that healthcare workers in the bronchoscopy suite could be accidentally exposed to Mycobacterium tuberculosis during bronchoscopy using radial probe EBUS if appropriate high-grade respiratory protection is not used. In addition, we identified several risk factors associated with an unexpected diagnosis of tuberculosis, such as age and distinct CT findings (low difference in HUs, concentric cavitation, and the presence of a satellite centrilobular nodule).

In previous studies on bronchoscopy using radial probe EBUS [9-15], although most of the study patients were diagnosed with malignant disease, $3.9-11.0 \%$ of patients were eventually diagnosed with pulmonary tuberculosis, rates that are similar to that found in this study (Table 6). During conventional bronchoscopy, the probability of unexpected diagnosis of pulmonary tuberculosis is known to range from $0.3 \%$ to $1.3 \%$ in low pulmonary tuberculosis prevalence regions, and $3.7 \%$ to $9.1 \%$ in intermediate or high prevalence regions [2]. Our results suggest that the risk of healthcare personnel being exposed to Mycobacterium tuberculosis during bronchoscopy using radial probe EBUS has been underestimated, with it being as high as that on conventional bronchoscopy.

Table 6. Diagnosis of pulmonary tuberculosis in previous studies on radial probe endobronchial ultrasound bronchoscopy 


\begin{tabular}{|c|c|c|c|c|c|}
\hline Authors & Year & Region & Design & No. lesions & No. tuberculosis \\
\hline Herth et al. ${ }^{12}$ & 2002 & Germany & Prospective & 50 & $2(4.0 \%)$ \\
\hline Shirakawa et al. ${ }^{11}$ & 2004 & Japan & Prospective & 50 & $2(4.0 \%)$ \\
\hline Kurimoto et al. ${ }^{10}$ & 2004 & Japan & Prospective & 150 & $12(8.0 \%)$ \\
\hline Herth et al. ${ }^{14}$ & 2006 & Germany & Prospective & 54 & $6(11.0 \%)$ \\
\hline Huang et al. ${ }^{13}$ & 2009 & Taiwan & Retrospective & 83 & $5(6.0 \%)$ \\
\hline Tamiya et al. ${ }^{15}$ & 2013 & Japan & Prospective & 68 & $3(4.4 \%)$ \\
\hline Oki et al. ${ }^{9}$ & 2015 & Japan & Prospective & 305 & $12(3.9 \%)$ \\
\hline
\end{tabular}

Our results indicate that patient age is one of the predicting factors for an unexpected diagnosis of pulmonary tuberculosis during bronchoscopy using radial probe EBUS, with patients younger than 58.5 years being more likely to have pulmonary tuberculosis. Previous epidemiological data show differences in age distribution between tuberculosis and lung cancer. Figure 2 shows a graph comparing the incidence of tuberculosis with that of lung cancer using data from the Korea Centers for Disease Control and Prevention $[4,28]$. The incidence of tuberculosis was similar from 30 s to 50 s, and then, it rapidly increases after $60 \mathrm{~s}$. The incidence of lung cancer is relatively low before $50 \mathrm{~s}$, whereas, it increases explosively after $60 \mathrm{~s}$. Taken together, before $60 \mathrm{~s}$, the incidence of tuberculosis is approximately twice higher than those of lung cancer. In addition, pulmonary tuberculosis is known to be one of the important differential diagnoses of PLLs, comprising more than $3 \%$ of all patients. Accordingly, our results suggest that the risk of a patient with a peripheral lung nodule being diagnosed with tuberculosis is significantly higher in younger patients than in elderly patients.

Kim et al [29]. reported that the presence of a satellite centrilobular nodule and a difference in HUs of less than 20 between pre-and post-enhancement images were useful predictors for benign nodules rather than malignant lesions, whereas Lee et al [30]. identified that the presence of concentric cavitation could suggest the possibility of tuberculosis. In the current study, we also found that a small difference in HUs (less than 4.8), concentric cavitation, and the presence of a satellite centrilobular nodule on CT were significantly associated with unexpected exposure to Mycobacterium tuberculosis during radial probe EBUS bronchoscopy. Moreover, two patients were finally diagnosed with both lung cancer and tuberculosis. Our results suggest that even if lung cancer is strongly suspected on $\mathrm{CT}$, if these risk factors associated with tuberculosis are present on CT scan, healthcare workers should be prepared for possible exposure to Mycobacterium tuberculosis.

This study has several limitations. First, the retrospective design of the study may have resulted in selection bias. Second, contrast-enhanced CT was performed on 817 patients (84.2\%); therefore, the 
difference in HU between pre- and post-enhancement images was not evaluated for all patients. Finally, all the data were obtained from the Republic of Korea, which is an intermediate tuberculosis prevalence region, and it may therefore be difficult to generalize the study results to other regions. To verify our results, a prospective study with a large study population recruited from multiple regions is needed.

\section{Conclusions}

We found that the incidence of unexpected diagnosis of pulmonary tuberculosis during radial probe EBUS bronchoscopy was 3.2\%. Generally, bronchoscopy using radial probe EBUS is performed for the diagnosis of a PLL that is suspected to be malignant; however, our results suggest that there are potential risks of exposure to Mycobacterium tuberculosis during the procedure. These risks are associated with a younger patient age (less than 58.5 years) and distinct CT findings of a small difference in HU between pre- and post-enhancement images (less than 4.8), concentric cavitation, and the presence of a satellite centrilobular nodule, which were all found to be independently associated with an increased probability of an unexpected diagnosis of pulmonary tuberculosis. Our findings suggest that healthcare workers in the bronchoscopy suite should wear a fit-tested N95 particulate respirator or higher-grade respiratory protection during radial probe EBUS bronchoscopy on patients with the identified risk factors.

\section{Abbreviations}

$\mathrm{Cl}$ = confidence interval; $\mathrm{CT}$ = computed tomography; $\mathrm{EBUS}$ = endobronchial ultrasound; $\mathrm{HU}=$ Hounsfield unit; $I Q R$ = interquartile range; $\mathrm{OR}$ = odds ratio; $\mathrm{PCR}=$ polymerase chain reaction; $\mathrm{PLL}$ = peripheral lung lesion

\section{Declarations}

\section{Ethics approval and consent to participate}

The Institutional Review Board of Pusan National University Hospital (IRB no. 1906-033-080) and Ulsan University Hospital (IRB no. 2020-07-011) approved this study. The requirement for informed consent was waived because of the retrospective nature of the study.

\section{Consent for publication}

Not applicable

\section{Availability of data and material}

Please contact author for data requests.

\section{Competing interests}

The authors declare that they have no competing interests. 


\section{Funding}

This research did not receive any specific grant from funding agencies in the public, commercial, or notfor-profit sectors.

\section{Authors' contributions}

HSC and JSE are the guarantors and take responsibility for the content of this manuscript, including the data and analysis. JSE conceived the initial idea and the study design. HSC, SB, IK and HYA linked the data, contributed to data analysis and interpreted results. HSC, SB and JSE drafted the manuscript and all authors revised manuscript and approved the final manuscript.

\section{Acknowledgements}

This work was supported by Department of Biostatistics, Biomedical Research Institute, Pusan National University Hospital.

\section{References}

1. Mehta AC, Prakash UB, Garland R, Haponik E, Moses L, Schaffner W, Silvestri G. American College of Chest Physicians and American Association for Bronchology [corrected] consensus statement: prevention of flexible bronchoscopy-associated infection. Chest. 2005; 128(3): 1742-1755.

2. Na HJ, Eom JS, Lee G, Mok J, Kim MH, Lee K, Kim KU, Lee MK. Exposure to Mycobacterium tuberculosis during Flexible Bronchoscopy in Patients with Unexpected Pulmonary Tuberculosis. PloS one. 2016; 11(5): e0156385.

3. Kim MH, Suh GY, Chung MP, Kim H, Kwon OJ, Lee JH, Lee NY, Koh W. The value of routinely culturing for tuberculosis during bronchoscopies in an intermediate tuberculosis-burden country. Yonsei Med J. 2007; 48(6): 969-972.

4. The Korea Academy of Tuberculosis and Respiratory Diseases. Korean Guidelines For Tuberculosis. 4th ed. Republic of Korea: Korea Centers for Disease Control and Prevention; 2020:218-219.

5. Criner GJ, Eberhardt R, Fernandez-Bussy S, Gompelmann D, Maldonado F, Patel N, Shah PL, Slebos D, Valipour A, Wahidi MM, Weir M, Herth FJ. Interventional Bronchoscopy: State-of-the-Art Review. Am J Rrespir Crit Care Med. 2020; 202(1): 29-50.

6. Steinfort DP, Khor YH, Manser RL, Irving LB. Radial probe endobronchial ultrasound for the diagnosis of peripheral lung cancer: systematic review and meta-analysis. Eur Respir J. 2011; 37(4): 902-910.

7. Wang Memoli JS, Nietert PJ, Silvestri GA. Meta-analysis of guided bronchoscopy for the evaluation of the pulmonary nodule. Chest. 2012; 142(2): 385-393.

8. Eom JS, Mok JH, Kim I, Lee MK. Radial probe endobronchial ultrasound using a guide sheath for peripheral lung lesions in beginners. BMC Pulm Med. 2018; 18(1): 137. 
9. Oki M, Saka H, Ando M, Asano F, Kurimoto N, Morita K, Kitagawa C, Kogure Y, Miyazawa T. Ultrathin Bronchoscopy with Multimodal Devices for Peripheral Pulmonary Lesions. A Randomized Trial. Am J Rrespir Crit Care Med. 2015; 192(4): 468-476.

10. Kurimoto N, Miyazawa T, Okimasa S, Maeda A, Oiwa H, Miyazu Y, Murayama M. Endobronchial ultrasonography using a guide sheath increases the ability to diagnose peripheral pulmonary lesions endoscopically. Chest. 2004; 126(3): 959-965.

11. Shirakawa T, Imamura F, Hamamoto J, Honda I, Fukushima K, Sugimoto M, Shirkakusa T. Usefulness of endobronchial ultrasonography for transbronchial lung biopsies of peripheral lung lesions. Respiration. 2004; 71(3): 260-268.

12. Herth F, Ernst A, Becker H. Endobronchial ultrasound-guided transbronchial lung biopsy in solitary pulmonary nodules and peripheral lesions. Eur Respir J. 2002; 20(4): 972-974.

13. Huang CT, Ho CC, Tsai YJ, Yu CJ, Yang PC. Factors influencing visibility and diagnostic yield of transbronchial biopsy using endobronchial ultrasound in peripheral pulmonary lesions. Respirology. 2009; 14(6): 859-864.

14. Herth F, Eberhardt R, Becker $H$, Ernst A. Endobronchial ultrasound-guided transbronchial lung biopsy in fluoroscopically invisible solitary pulmonary nodules: a prospective trial. Chest. 2006; 129(1): 147150.

15. Tamiya M, Okamoto N, Sasada S, Shiroyama T, Morishita N, Suzuki H, Yoshida E, Hirashima T, Kawahara K, Kawase I. Diagnostic yield of combined bronchoscopy and endobronchial ultrasonography, under $\mathrm{L}$ ung $\mathrm{P}$ oint guidance for small peripheral pulmonary lesions. Respirology. 2013; 18(5): 834-839.

16. National Lung Screening Trial Research Team, Aberle DR, Adams AM, Berg CD, Black WC, Clapp JD, Fagerstrom RM, Gareen IF, Gatsonis C, Marcus PM, Sicks JD. Reduced lung-cancer mortality with lowdose computed tomographic screening. N Engl J Med. 2011;365:395-409.

17. Wood DE, Kazerooni EA, Baum SL, Eapen GA, Ettinger DS, Hou L, Jackman DM, Klippenstein D, Kumar R, Lackner RP, Leard LE, Lennes IT, Leung ANC, Makani SS, Massion PP, Mazzone P, Merritt RE, Meyers BF, Midthun DE, Pipavath S, Pratt C, Reddy C, Reid ME, Rotter AJ, Sachs PB, Schabath MB, Schiebler ML, Tong BC, Travis WD, Benjamin W, Yang SC, Gregory KM, Hughes M. Lung Cancer Screening, Version 3.2018, NCCN Clinical Practice Guidelines in Oncology. J Natl Compr Canc Netw. 2018; 16(4): 412-441.

18. Kuiper J, Heideman D, Thunnissen E, Paul MA, Wijk AW, Postmus PE, Smit EF. Incidence of T790M mutation in (sequential) rebiopsies in EGFR-mutated NSCLC-patients. Lung cancer. 2014; 85(1): 1924.

19. Lee KM, Lee G, Kim A, Mok J, Lee JW, Jeong YJ, Jo E, Kim MH, Lee K, Kim KU, Park H, Lee MK, Eom JS. Clinical outcomes of radial probe endobronchial ultrasound using a guide sheath for diagnosis of peripheral lung lesions in patients with pulmonary emphysema. Respir Res. 2019; 20(1): 177.

20. Kikuchi E, Yamazaki K, Sukoh N, Kikuchi J, Asahina H, Imura M, Onodera Y, Kurimoto N, Kinoshita I, Nishimura M. Endobronchial ultrasonography with guide-sheath for peripheral pulmonary lesions. 
Eur Respir J. 2004; 24(4): 533-537.

21. Naidich DP, Sussman R, Kutcher WL, Aranda CP, Garay SM, Ettenger NA. Solitary pulmonary nodules: CT-bronchoscopic correlation. Chest. 1988; 93(3): 595-598.

22. Furuya K, Murayama S, Soeda H, Murakami J, Ichinose Y, Yabuuchi H, Katsuda Y, Koga M, Masuda K. New classification of small pulmonary nudules by margin characteristics on highresolution CT. Acta Radiol. 1999; 40(5): 496-504.

23. Wei J, Tang D, Nie Y, Chen J, Peng L. Clinical characteristics and prognosis of nonsurgically treated patients with pneumonic-type adenocarcinoma. Medicine (Baltimore). 2019; 98(18): e15420.

24. Takamochi K, Nagai K, Yoshida J, Suzuki K, Ohde Y, Nishimura M, Sasaki S, Nishiwaki Y. Pathologic NO status in pulmonary adenocarcinoma is predictable by combining serum carcinoembryonic antigen level and computed tomographic findings. J Thorac Cardiovasc Surg. 2001; 122(2): 325-330.

25. Yi CA, Lee KS, Kim EA, Han J, Kim H, Kwon OJ, Jeong YJ, Kim S. Solitary pulmonary nodules: dynamic enhanced multi-detector row CT study and comparison with vascular endothelial growth factor and microvessel density. Radiology. 2004; 233(1): 191-199.

26. Kim HO, Seon HJ, Lee D, Shin SS, Kim YH, Kang HK. Pulmonary Tuberculosis Mimicking Lung Cancer on Radiological Findings: Evaluation of Chest CT Findings in Pathologically Proven 76 Patients. J Korean Soc Radiol. 2012;67(3):161-168.

27. George PM, Mehta M, Dhariwal J, Singanayagam A, Raphael CE, Salmasi M, Connell DW, Molyneaux P, Wickremasinghe M, Jepson A, Kon OM. Post-bronchoscopy sputum: improving the diagnostic yield in smear negative pulmonary TB. Respir Med. 2011; 105(11): 1726-1731.

28. Korea Central Cancer Registry. Annual report of cancer statistics in Korea in 2017. Republic of Korea: Ministry of Health and Welfare; 2019:62-63.

29. Kim H, Kang SJ, Suh GY, Chung MP, Kwon OJ, Rhee CH, Jung KJ, Kim TS, Lee KS. Predictors for benign solitary pulmonary nodule in tuberculosis-endemic area. Korean J Intern Med. 2001; 16(4): 236.

30. Lee KS, Park KS, Choi WS, Yoon Y, Lim JH. Radiological analysis of solitary cavitary lesions of the lung: Differentiation between lung cancer and tuberculosis. J Korean Soc Radiol. 1989; 25(3): 410415.

31. Deslauriers J, Brisson J, Cartier R, Fournier M, Gagnon D, Piraux M, Beaulieu M. Carcinoma of the lung. Evaluation of satellite nodules as a factor influencing prognosis after resection. J Thorac Cardiovasc Surg. 1989;97(4):504-12.

32. Koh W-J, Lee KS, Kwon OJ, Jeong YJ, Kwak S-H, Kim TS. Bilateral bronchiectasis and bronchiolitis at thin-section CT: diagnostic implications in nontuberculous mycobacterial pulmonary infection. Radiology. 2005; 235(1): 282-8.

33. Kim HY, Im JG, Goo JM, Kim JY, Han SK, Lee JK, Song JW. Bronchial anthracofibrosis (inflammatory bronchial stenosis with anthracotic pigmentation): CT findings. AJR Am J Roentgenol. 2000; 174(2): 523-7. 
34. Hansell DM, Bankier AA, MacMahon H, McLoud TC, Muller NL, Remy J. Fleischner Society: glossary of terms for thoracic imaging. Radiology. 2008;246(3):697-722.

35. Medlar EM. The pathogenesis of minimal pulmonary tuberculosis; a study of 1,225 necropsies in cases of sudden and unexpected death. Am Rev Tuberc. 1948;58(6):583-611.

36. Misumi S, Lynch DA. Idiopathic pulmonary fibrosis/usual interstitial pneumonia: imaging diagnosis, spectrum of abnormalities, and temporal progression. Proc Am Thorac Soc. 2006;3(4):307-14.

37. Abramowitz Y, Simanovsky N, Goldstein MS, Hiller N. Pleural effusion: characterization with CT attenuation values and CT appearance. AJR Am J Roentgenol. 2009;192(3):618-23.

\section{Figures}

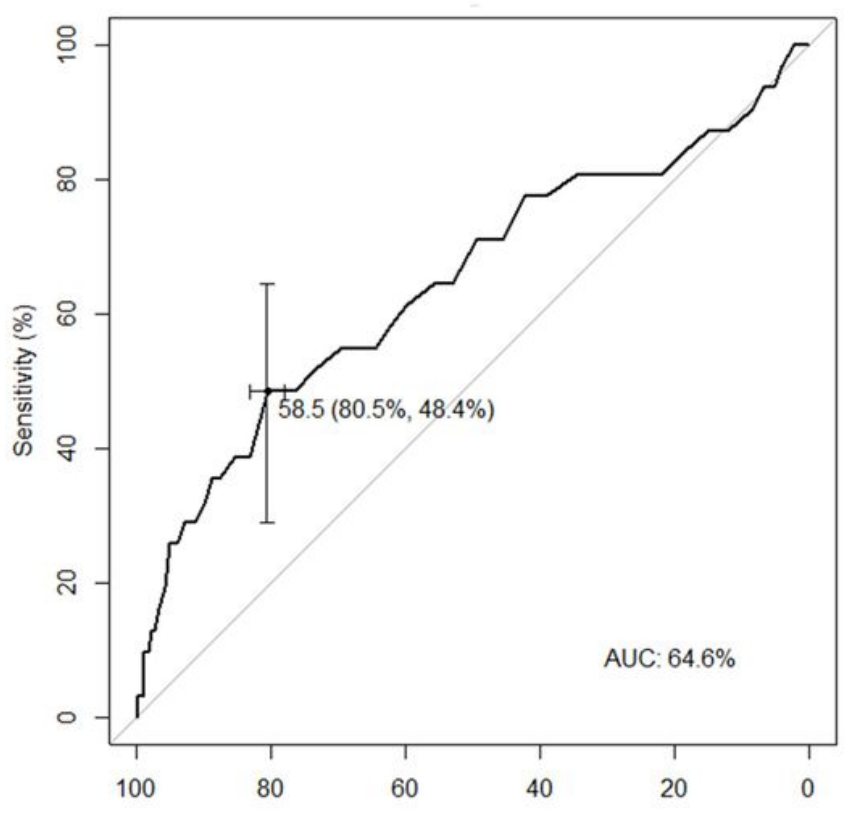

(A) Age

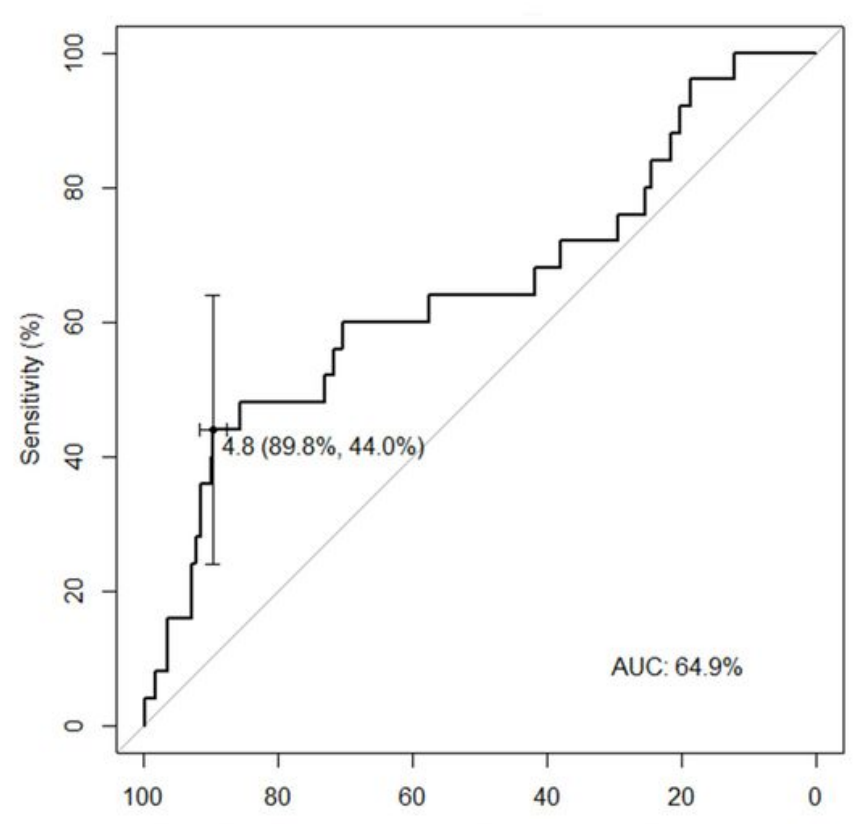

(B) Difference of Hounsfield unit

\section{Figure 1}

Receiver operating characteristics (ROC) curves for predicting unexpected diagnosis of pulmonary tuberculosis. (A) ROC curve of age. (B) ROC curve of the difference in Hounsfield units between pre-and post-enhancement images. 


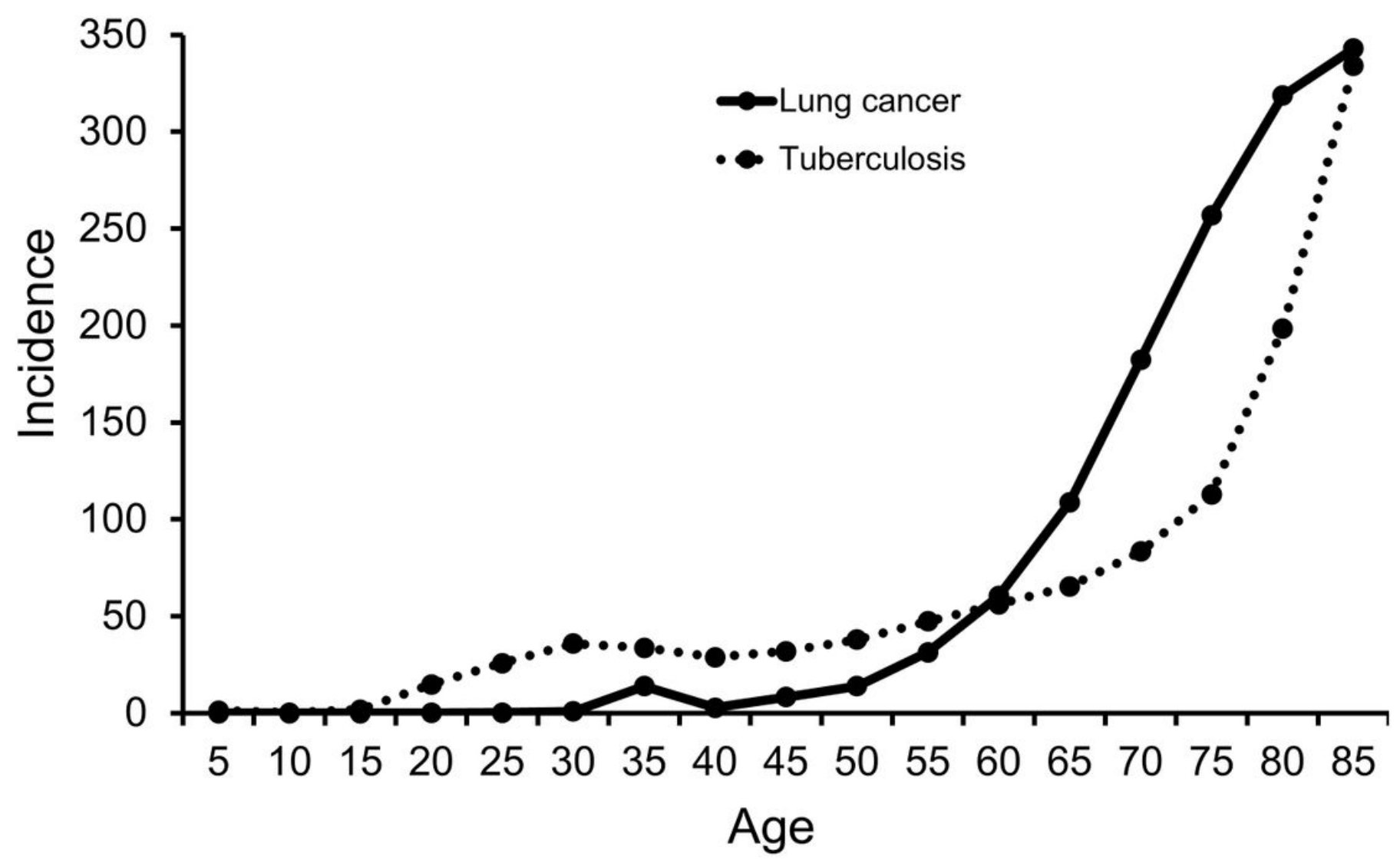

Figure 2

Comparison of the incidence of tuberculosis and lung cancer according to age in the Republic of Korea (100 000 persons per year).

\section{Supplementary Files}

This is a list of supplementary files associated with this preprint. Click to download.

- Additionalfile2.docx

- Additionalfile1.docx

- AdditionalFiles.docx 